\title{
openheart Assessing the risk of preterm birth for newborns with congenital heart defects conceived following infertility treatments: a population-based study
}

\author{
Karim Tararbit, ${ }^{1}$ Nathalie Lelong, ${ }^{1}$ François Goffinet, ${ }^{1,2}$ Babak Khoshnood, ${ }^{1}$ the \\ EPICARD Study Group
}

To cite: Tararbit K, Lelong N, Goffinet $F$, et al. Assessing the risk of preterm birth for newborns with congenital heart defects conceived following infertility treatments: a population-based study. Open Heart 2018;5:e000836. doi:10.1136/ openhrt-2018-000836

Received 17 April 2018 Revised 7 August 2018 Accepted 31 August 2018

Check for updates

(c) Author(s) (or their employer(s)) 2018. Re-use permitted under CC BY-NC. No commercial re-use. See rights and permissions. Published by BMJ.

${ }^{1}$ INSERM, UMR 1153 , Obstetrical, Perinatal and Pediatric Epidemiology Research Team (EPOPé), Center for Epidemiology and Statistics, Sorbonne Paris Cité (CRESS), DHU Risks in Pregnancy, Paris Descartes University, Paris, France

${ }^{2}$ Maternité Port Royal, Hôpital Cochin Saint-Vincent-de-Paul, Assistance Publique Hôpitaux de Paris, Université ParisDescartes, Paris, France

Correspondence to Karim Tararbit; karim.tararbit@ inserm.fr

\section{ABSTRACT}

Objectives To quantify the risk of preterm birth (PTB) for newborns with congenital heart defects (CHDs) conceived following infertility treatments, and to examine the role of multiple pregnancies in the association between infertility treatments and PTB for newborns with CHD.

Methods We used data from a population-based, prospective cohort study (EPICARD EPIdémiologie des CARDiopathies congénitales) including 2190 newborns with $\mathrm{CHD}$ and excluding cases with atrial septal defects born to women living in the Greater Paris area between May 2005 and April 2008. Statistical analysis included logistic regression to take into account potential confounders (maternal characteristics, invasive prenatal testing, CHD prenatal diagnosis, medically induced labour/ caesarean section before labour, birth year). The role of multiple pregnancies was assessed using a path-analysis approach, allowing decomposition of the total effect of infertility treatments on the risk of PTB into its indirect (mediated by the association between infertility treatments and multiple pregnancies) and direct (mediated by mechanisms other than multiple pregnancies) effects. Results PTB occurred for $40.6 \%(95 \% \mathrm{Cl} 28.7$ to 52.5) of newborns with $\mathrm{CHD}$ conceived following infertility treatments vs $12.7 \%(95 \% \mathrm{Cl} 11.3$ to 14.2$)$ for spontaneously conceived newborns $(p<0.001)$. After taking into account potentially confounding factors, infertility treatments were associated with a 5.0-fold higher odds of PTB (adjusted OR=5.0, 95\% Cl 2.9 to 8.6). Approximately two-thirds of this higher risk of PTB associated with infertility treatments was an indirect effect (ie, due to multiple pregnancies) and one-third was a direct effect (ie, not mediated by multiple pregnancies).

Conclusion Newborns with CHD conceived following infertility treatments are at a particularly high risk of PTB, exposing over $40 \%$ of them to the 'double jeopardy' of CHD and PTB.

\section{INTRODUCTION}

Treatments of infertility are the different methods used to achieve pregnancy in case of female and/or male infertility, including induction of ovulation (IO) and assisted reproductive techniques (ART) stricto sensu

\section{Key questions}

What is already known about this subject?

- In general, newborns conceived following infertility treatments are at a higher risk of preterm birth (PTB).

- The available literature also suggests that infertility treatments may increase the risk of congenital heart defects (CHDs) and that CHD, in and of itself, is associated with a higher risk of PTB.

- It is not known however to what extent newborns with CHD conceived following infertility treatments may be at a higher risk of PTB, thus exposing them to the 'double jeopardy' of CHD and PTB.

What does this study add?

- These results suggest that newborns with CHD conceived following infertility treatments are at a particularly high risk of PTB, thus exposing over $40 \%$ of them to the 'double jeopardy' of CHD and PTB.

- Our results also suggest that two-thirds of this higher risk of PTB is due to multiple pregnancies, whereas a third is mediated by other mechanisms ('direct' effect of infertility treatments).

- The extent to which our results may be generalisable to other populations or different practice settings for infertility treatments requires further study.

How might this impact on clinical practice?

- The extent to which our results may be generalisable to other populations or different practice settings for infertility treatments requires further study.

such as in vitro fertilisation (IVF) and intracytoplasmic sperm injection (ICSI). These methods are increasingly used worldwide, and IVF alone accounted for nearly $1.6 \%$ of the total births in 2014 in the USA. ${ }^{1}$

Adverse perinatal outcomes (eg, low birth weight, preterm birth PTB) are more frequent in pregnancies conceived following infertility treatments as compared with spontaneously conceived pregnancies. ${ }^{1-4}$ Infertility treatments are also associated with a higher risk 
of congenital anomalies, ${ }^{5-7}$ in particular a higher risk of congenital heart defects (CHDs). ${ }^{5-11}$

CHD is the most common group of congenital anomalies at birth with an overall total prevalence of 8.0 per 1000 births. ${ }^{12}$ Despite progress in their medical and surgical management, CHD remains an important cause of morbidity and the first cause of infant death by malformation. ${ }^{12}{ }^{13}$ Newborns with CHD are also at higher risk of adverse perinatal outcomes such as small for gestational age $^{14}$ and PTB, ${ }^{15} 16$ which in turn are associated with higher morbidity and mortality. ${ }^{17} 18$

Newborns with CHD conceived following treatments of infertility may be exposed to both the adverse effects of CHD and treatments of infertility, including in particular PTB and multiple pregnancies. The degree of a higher risk of PTB for newborns with CHD conceived following treatments of infertility is not known. Moreover, the role of multiple pregnancies in the association between treatments of infertility and PTB in newborns with CHD has not been assessed. ${ }^{12}$

Using data from a large, prospective, population-based cohort of children with CHD (the EPIdémiologie des CARDiopathies congénitales (EPICARD) study), ${ }^{13}$ we (1) assessed the risk of PTB for newborns with CHD conceived following treatments of infertility (IO, IVF, ICSI) and compared it with the risk of PTB for newborns with CHD conceived without treatments of infertility; and (2) used a path-analysis approach to assess the role of multiple pregnancies in the association between treatments of infertility and PTB for newborns with CHD.

\section{MATERIALS AND METHODS \\ Data source}

The EPICARD study ${ }^{13}$ is a prospective, population-based cohort study of all children with a CHD born to women living in the Greater Paris area (Paris and its surrounding suburbs) between 2005 and 2008 regardless of place of delivery (total number of births: 317 538). The principal objectives of the study are to use population-based data from a large cohort of patients with CHD to (1) estimate the total and live birth prevalence, (2) examine timing of diagnosis and assess medical and surgical management of children with CHD, (3) evaluate neonatal mortality and morbidity and neurodevelopmental outcomes of children with CHD at the age of 8 , and (4) identify the factors associated with their health outcomes, especially the role of events during the neonatal period and of the initial medical and surgical management. All cases (live births, pregnancy terminations, fetal deaths) diagnosed in the prenatal period or up to 1 year of age in the birth cohorts between 1 May 2005 and 30 April 2008 were eligible for inclusion. The total number of cases included in the study was 2867, including 2348 live newborns (82\%), 466 pregnancy terminations $(16.2 \%)$ and 53 fetal deaths $(1.8 \%)$. The total prevalence of CHD was 9.0 per 1000 in our population. Diagnoses were confirmed in specialised paediatric cardiology departments and for the majority of pregnancy terminations and fetal deaths by fetopathologist examination; for others in which a pathology exam could not be done (26\%), the diagnoses were confirmed by consensus by a paediatric cardiologist and a specialist in echocardiography based on the results of prenatal echocardiography examination.

For this study, we excluded cases of pregnancy terminations and fetal deaths. We also excluded isolated cases of atrial septal defect (ASD) to minimise ascertainment bias (figure 1). Indeed, echocardiography is more often performed in preterm newborns and may be conducted to diagnose minor ASD that would have remained undiagnosed otherwise.

\section{Methods}

The main outcome measure was the probability (odds) of PTB (birth $<37$ weeks of gestation). We quantified and compared the probability of PTB for newborns with CHD conceived after infertility treatments versus those spontaneously conceived for (1) all CHD; (2) isolated CHD (ie, without associated chromosomal or other system anomalies); and (3) major isolated CHD, that is, isolated CHD-ventricular septal defect (VSD) excluded. These categories were chosen as a previous study ${ }^{15}$ showed that in general the risk of PTB is variable across these categories.

Data on exposure to infertility treatments were obtained from medical records. We analysed exposure to infertility treatments with all methods combined (IO, IVF \pm ICSI), as well as separately for ARTs only (IVF \pm ICSI). We did not have sufficient power however to assess the risk of PTB for cases including IO only.

Using logistic regression, we adjusted the association between infertility treatments and risk (odds) of PTB for the following potentially confounding factors: maternal sociodemographic characteristics (age, occupation and geographical origin), diabetes mellitus, vaginal bleeding during pregnancy, gravidity and year of birth. These factors are known to be associated with the risk of PTB, although their exact relation with the risk of CHD is not completely documented. ${ }^{19} 20$ Maternal age was coded in five categories $(<20,20-29,30-34,35-39$ and $>39)$. Gravidity was coded in two categories: primigravida and multigravida. Maternal occupation was coded in five categories (professional, intermediate, administrative/public service, other and none) following the French National Institute of Statistics and Economic Studies (INSEE) classification. Geographical origin was coded in four categories: French, North African, Sub-Saharan African and other countries. Plurality was classified into two categories: single pregnancies and twins or higher order pregnancies. Year of birth was considered as a continuous variable. Other factors considered as potential confounders were related to management of pregnancy and delivery: invasive prenatal testing (amniocentesis, chorionic villus sampling), prenatal diagnosis of CHD, medical induction of labour or elective caesarean section before labour (for fetal and/or maternal indications). 
$2867 \mathrm{CHD}$ included in Epicard study (EPIDémiologie des

CARDiopathies congénitales)

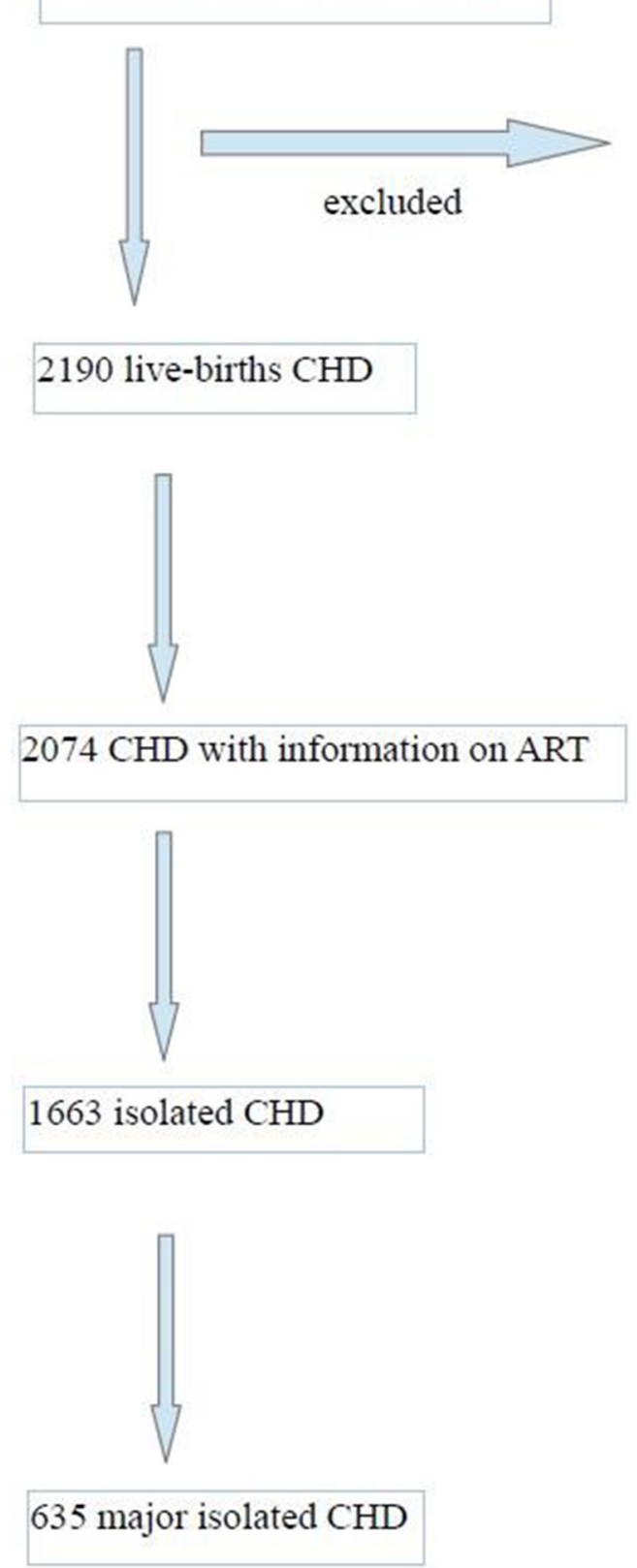

466 TOPFA

53 fetal deaths

158 isolated ASD

5 missing data on gestational age

Figure 1 Flow chart of the study population. ASD, atrial septal defect; CHD, congenital heart defect; TOPFA, termination of pregnancy for fetal anomaly.

We also conducted analyses with further adjustment for in utero growth retardation.

\section{Statistical analysis}

We used standard statistical tests for univariable analyses of the differences between newborns conceived following infertility treatments and spontaneously conceived newborns $\left(\chi^{2}\right.$, Fisher's exact test and t-test). Differences in the odds of PTB for newborns conceived following infertility treatments and spontaneously conceived newborns were assessed using logistic regression models after taking into account the potentially confounding factors listed previously.

To assess the mediating role of multiple pregnancies in the association between infertility treatments and PTB, we conducted a path analysis ${ }^{21}{ }^{22}$ that allows to decompose the total effect associated with infertility treatments into an indirect effect (ie, mediated by the association between infertility treatments and multiple pregnancies) and a direct effect (ie, not mediated by multiple pregnancies). We used a path-analysis model that is based on a counterfactual ('what if') approach which may be 
conceptually summarised as the answer to: "What would be the risk of PTB associated with infertility treatments if fetuses conceived following infertility treatments had the same probability of multiple pregnancies as spontaneously-conceived newborns?'

The statistical significance level was set at $\alpha=0.05$ and all tests were two-sided. Analyses were done with Stata V.12 software.

\section{RESULTS}

\section{Population characteristics}

The EPICARD study included 2867 CHDs. After excluding pregnancy terminations, fetal deaths, isolated ASD and cases with missing information on gestational age, the overall study population included 2190 live newborns with CHD (figure 1). Complete information on infertility treatments exposure was available for 2074 (94.7\%) of these cases. Among these 2074 cases, 1663 were isolated CHD (ie, CHD without associated chromosomal anomalies or anomalies of other system), which comprised 635 major isolated CHDs (ie, isolated CHD-VSD excluded).

Conception following infertility treatments was found for 3.3\% (69 of 2074) of cases, among whom 2.8\% (58 of 2074) following ART (IVF \pm ICSI).

Table 1 summarises the characteristics of the study population according to infertility treatments exposure. For all variables but two (maternal occupation 5.8\% and vaginal bleeding during pregnancy $4.7 \%$ ), there were less than $1 \%$ of missing data. Mothers of newborns with CHD conceived following infertility treatments were older (34.8 vs 31.2 years, $\mathrm{p}<0.001$ ) and more often in the highest occupation category 'professional' (40.0 vs $23.4 \%, \mathrm{p}=0.003$ ) as compared with mothers of newborns with CHD conceived spontaneously. Multiple pregnancies (43.4 vs 3.2\%, $\mathrm{p}<0.001)$ and elective caesarean section (23.2 vs $12.0 \%, \mathrm{p}=0.005)$ were significantly more frequent after infertility treatments as compared with spontaneous pregnancies.

Table 2 summarises the proportions of exposure to infertility treatments according to the characteristics of the population. Conceptions following infertility treatments increased with maternal age (from $0 \%$ for mothers $<20$ to $6.3 \%$ for mothers $\geq 40, \mathrm{p}<0.001$ ), and were highest in the occupation category 'professional' and lowest for unemployed mothers $(5.5 \%$ and $1.4 \%$, respectively, $\mathrm{p}=0.003)$. Conception following infertility treatments was found in $31.9 \%$ of multiple pregnancies vs $2.0 \%$ of singletons $(\mathrm{p}<0.001)$. Infertility treatments exposure occurred in $6.3 \%$ of newborns delivered after elective caesarean section vs $2.9 \%$ of other cases $(\mathrm{p}=0.005)$.

\section{Probability of PTB}

Table 3 summarises the univariable and multivariable analyses of the probability (odds) of PTB in relation to infertility treatments exposure.
Table 1 Sociodemographic characteristics of newborns with congenital heart defect (CHD) exposed versus nonexposed to infertility treatments

\begin{tabular}{|c|c|c|c|}
\hline & $\begin{array}{l}\text { Newborns } \\
\text { conceived } \\
\text { following } \\
\text { infertility } \\
\text { treatments }\end{array}$ & $\begin{array}{l}\text { Spontaneously } \\
\text { conceived } \\
\text { newborns } \\
\end{array}$ & \\
\hline Characteristics & n (\%)* & $\mathrm{n}(\%)^{*}$ & $P$ values \\
\hline \multicolumn{4}{|l|}{ Mother } \\
\hline \multicolumn{4}{|l|}{ Age (years) } \\
\hline Mean (SD) & $34.8(4.7)$ & $31.2(5.6)$ & $<0.001$ \\
\hline$<20$ & $0(0.0)$ & $32(1.6)$ & $<0.001$ \\
\hline $20-29$ & $6(8.7)$ & $732(36.6)$ & \\
\hline $30-34$ & $32(46.4)$ & $691(34.5)$ & \\
\hline $35-39$ & $21(30.4)$ & $397(19.8)$ & \\
\hline$\geq 40$ & $10(14.5)$ & $149(7.5)$ & \\
\hline Missing $†$ & $0(0.0)$ & $4(0.2)$ & \\
\hline \multicolumn{4}{|l|}{ Geographical origin } \\
\hline France & $33(47.8)$ & 957 (47.9) & 0.557 \\
\hline North Africa & $11(15.9)$ & $397(19.9)$ & \\
\hline Sub-Saharan Africa & $8(11.6)$ & $274(13.7)$ & \\
\hline Other & $17(24.6)$ & $370(18.5)$ & \\
\hline Missing $†$ & $0(0.0)$ & $7(0.4)$ & \\
\hline \multicolumn{4}{|l|}{ Occupation } \\
\hline None & $8(12.3)$ & $550(29.0)$ & 0.003 \\
\hline Professional & $26(40.0)$ & $444(23.4)$ & \\
\hline Intermediate & $9(13.9)$ & $376(19.8)$ & \\
\hline $\begin{array}{l}\text { Administrative/public } \\
\text { service }\end{array}$ & $7(10.8)$ & $216(11.4)$ & \\
\hline Other & $15(23.1)$ & $313(16.5)$ & \\
\hline Missing & $4(5.3)$ & $106(5.8)$ & \\
\hline \multicolumn{4}{|l|}{ Gravidity } \\
\hline 1 & $32(46.4)$ & $678(33.8)$ & 0.080 \\
\hline 2 & $19(27.5)$ & $604(30.1)$ & \\
\hline$>2$ & $18(26.1)$ & $722(36.0)$ & \\
\hline Missing & $0(0.0)$ & $106(0.05)$ & \\
\hline Diabetes mellitus & $2(2.9)$ & $95(4.8)$ & 0.770 \\
\hline Missing $†$ & $0(0.0)$ & $6(0.3)$ & \\
\hline \multicolumn{4}{|l|}{ Pregnancy } \\
\hline \multicolumn{4}{|l|}{ Plurality } \\
\hline Singletons & 39 (56.5) & $1941(96.8)$ & $<0.001$ \\
\hline Multiple & $30(43.4)$ & $64(3.2)$ & \\
\hline Missing† & $0(0.0)$ & $0(0.0)$ & \\
\hline Small for gestational age & $19(27.5)$ & $261(13.0)$ & 0.001 \\
\hline Missing & $0(0.0)$ & $2(0.1)$ & \\
\hline Vaginal bleeding & $1(1.5)$ & $22(1.15)$ & 0.561 \\
\hline Missing & $0(0.0)$ & $98(4.9)$ & \\
\hline Invasive prenatal screening & $16(23.2)$ & $422(21.1)$ & 0.675 \\
\hline Missing† & $0(0.0)$ & $4(0.2)$ & \\
\hline Prenatal diagnosis of $\mathrm{CHD}$ & $(15.9)$ & $433(21.6)$ & 0.260 \\
\hline
\end{tabular}

Continued 


\begin{tabular}{|c|c|c|c|}
\hline & $\begin{array}{l}\text { Newborns } \\
\text { conceived } \\
\text { following } \\
\text { infertility } \\
\text { treatments }\end{array}$ & $\begin{array}{l}\text { Spontaneously } \\
\text { conceived } \\
\text { newborns }\end{array}$ & \\
\hline Characteristics & n (\%)* & n (\%)* & $P$ values \\
\hline Missing & $0(0.0)$ & $0(0.0)$ & \\
\hline Induced labour & $7(10.1)$ & $315(15.8)$ & 0.204 \\
\hline Missing† & $0(0.0)$ & $9(0.5)$ & \\
\hline Elective caesarean section & $16(23.2)$ & $239(12.0)$ & 0.005 \\
\hline Missing† & $0(0.0)$ & $11(0.6)$ & \\
\hline
\end{tabular}

${ }^{*}$ Cases or controls without missing data used as a denominator to calculate the \%.

$\dagger \%$ of missing data calculated with the total numbers of cases and controls.

\section{All CHDs}

PTB occurred for $40.6 \%$ (95\% CI 28.7 to 52.5) of newborns conceived following infertility treatments (all methods combined) vs $12.7 \%$ (95\% CI 11.3 to 14.2) of spontaneously conceived newborns $(\mathrm{p}<0.001)$. PTB was medically induced for $35.7 \%$ of newborns conceived following infertility treatments vs $25.1 \%$ of spontaneously conceived newborns; however, this difference was not statistically significant $(\mathrm{p}=0.332)$.

Exposure to infertility treatments (all methods combined) was associated with a 4.7 -fold higher odds of PTB (unadjusted OR=4.7, 95\% CI 2.8 to 7.7 ). After taking into account potentially confounding factors (maternal age, occupation and geographical origin, diabetes mellitus, vaginal bleeding during pregnancy, gravidity, year of birth, invasive prenatal testing, prenatal diagnosis of CHD, mode of delivery), infertility treatments were associated with a fivefold higher odds of PTB (adjusted $\mathrm{OR}=5.0,95 \%$ CI 2.9 to 8.6). IVF \pm ICSI was associated with a statistically significant increase in the risk of PTB (adjusted OR=5.4, 95\% CI 3.0 to 9.7).

\section{Isolated CHD}

For isolated CHD, the results were generally similar to those found for all cases of CHD (all methods combined: adjusted $\mathrm{OR}=5.3,95 \%$ CI 2.9 to 9.8; for IVF \pm ICSI: adjusted $\mathrm{OR}=5.7,95 \%$ CI 3.0 to 10.8 ).

\section{Major isolated $\mathrm{CHD}$}

For major isolated CHD, infertility treatments (all methods combined) were associated with a 3.6-fold higher odds of PTB (adjusted OR=3.6, 95\% CI 1.4 to 9.4). IVF \pm ICSI was associated with a statistically significant increase in the risk of PTB (adjusted OR=4.0, 95\% CI 1.4 to 11.2).

\section{Role of multiple pregnancies}

Table 4 summarises the path-analysis results for the decomposition of the total effect of infertility treatments
Table 2 Comparison of infertility treatments ${ }^{*}$ exposure according to sociodemographic characteristics

\begin{tabular}{|c|c|c|}
\hline & n (\%)† & $P$ values \\
\hline \multicolumn{3}{|l|}{ Mother } \\
\hline \multicolumn{3}{|l|}{ Age (years) } \\
\hline$<20$ & $32(0.0)$ & $<0.001$ \\
\hline $20-29$ & $738(0.8)$ & \\
\hline $30-34$ & $723(4.4)$ & \\
\hline $35-39$ & $418(5.0)$ & \\
\hline$\geq 40$ & $159(6.3)$ & \\
\hline \multicolumn{3}{|l|}{ Geographical origin } \\
\hline France & $990(3.3)$ & 0.557 \\
\hline North Africa & $408(2.7)$ & \\
\hline Sub-Saharan Africa & $282(2.8)$ & \\
\hline Other & $387(4.4)$ & \\
\hline \multicolumn{3}{|l|}{ Occupation } \\
\hline None & $558(1.4)$ & 0.003 \\
\hline Professional & $470(5.5)$ & \\
\hline Intermediate & $385(2.3)$ & \\
\hline Administrative/public service & $223(3.1)$ & \\
\hline Other & $328(4.6)$ & \\
\hline \multicolumn{3}{|l|}{ Gravidity } \\
\hline 1 & $710(4.5)$ & 0.080 \\
\hline 2 & $623(3.1)$ & \\
\hline$>2$ & $740(2.4)$ & \\
\hline \multicolumn{3}{|l|}{ Diabetes mellitus } \\
\hline No & $1971(3.4)$ & 0.770 \\
\hline Yes & $97(2.1)$ & \\
\hline
\end{tabular}

Pregnancy

Multiplicity

Singletons

$1980(2.0)$

$<0.001$

Multiple

$94(31.9)$

Small for gestational age

No

$1792(2.8)$

Yes

$280(6.8)$

Vaginal bleeding

No

$1953(3.5)$

Yes

$23(4.4)$

Invasive prenatal screening

$$
\text { No } 1632(3.3)
$$

Yes

438 (3.7)

Prenatal diagnosis of congenital heart defect

$$
\begin{array}{lr}
\text { No } & 1630(3.6) \\
\text { Yes } & 444(2.5)
\end{array}
$$

Induced labour

$\begin{array}{lr}\text { No } & 1743(3.6) \\ \text { Yes } & 322(2.2)\end{array}$




\begin{tabular}{|c|c|c|}
\hline & n (\%)t & $P$ values \\
\hline \multicolumn{3}{|c|}{ Elective caesarean section } \\
\hline No & $1808(2.9)$ & 0.005 \\
\hline Yes & $255(6$ & \\
\hline
\end{tabular}

${ }^{*}$ Infertility treatments included induction of ovulation, in vitro fertilisation and intracytoplasmic sperm injection.

$\dagger \%$ calculated with the total of cases or controls without missing data as a denominator.

on the risk of PTB into direct and indirect (ie, mediated by multiple pregnancies) components.

This analysis suggested that about two-thirds of the overall higher odds of PTB associated with infertility treatments were due to the higher probability of multiple pregnancies following infertility treatments (the indirect effect of infertility treatments on the risk of PTB mediated by multiple pregnancies), whereas one-third of the total effect on the risk of PTB associated with infertility treatments was not due to the higher risk of multiple pregnancies (the direct effect of infertility treatments on the risk of PTB). For IVF \pm ICSI, the estimated size of the indirect effect relative to their total effects was similar to that found for all methods combined $(66.7 \%)$.

For isolated CHD, the results were close to those observed for all CHDs analysed together. For major isolated CHDs, the results for all methods combined $(57.7 \%)$ and for IVF \pm ICSI $(62.7 \%)$ were slightly lower than those observed for all CHDs.

Finally, further adjustment for in utero growth retardation did not modify substantially neither our estimates of the risk of PTB associated with infertility treatments nor the quantification of the effect of multiple pregnancies in this association (data not shown).

\section{DISCUSSION}

In this study, using data on 2074 newborns from a population-based, prospective cohort study of children with CHD (the EPICARD study), ${ }^{13}$ we assessed the risk of PTB in newborns with $\mathrm{CHD}$ conceived following infertility treatments (IO, IVF and ICSI). We also examined the role of multiple pregnancies in the association between infertility treatments and PTB.

Our results show that infertility treatment conception notably increases the risk of PTB in newborns with CHD, as we found that $40 \%$ of newborns with CHD conceived following infertility treatments (all methods combined) were born preterm, compared with $12 \%$ for those conceived spontaneously. After taking into account potentially confounding factors, infertility treatments were associated with a fivefold higher odds of PTB for newborns with CHD. In the general population/non-malformed newborns, infertility treatments are associated with a 1.5-fold to 2-fold higher risk of PTB. ${ }^{2}{ }^{4}$ Consequently, the magnitude of the effect of infertility treatments on the risk of PTB appears substantially higher in the case of CHD as compared with that observed in the general population. Newborns with CHD conceived following infertility treatments are therefore particularly at risk of PTB with its attendant adverse short-term and long-term outcomes. ${ }^{23}$ Moreover, when we restricted our analysis to spontaneous births (not medically induced births), the risk of PTB in newborns with CHD conceived following infertility treatments remained much higher than in newborns with CHD conceived without infertility treatments (data not shown).

Using a path-analysis model, we found that about two-thirds of the total effect of infertility treatments on the risk of PTB in newborns with CHD was due to (mediated by) multiple pregnancies (the indirect effect), whereas

Table 3 Analyses of the association between infertility treatments and risk of preterm birth in newborns with CHD

\begin{tabular}{|c|c|c|c|c|c|c|c|c|}
\hline CHD & Infertility treatments & $\mathbf{n}$ & $\%(95 \% \mathrm{Cl})$ & $P$ values & $\begin{array}{l}\text { Unadjusted } \\
\text { OR }^{\star}\end{array}$ & $95 \% \mathrm{Cl}$ & $\begin{array}{l}\text { Adjusted† } \\
\text { OR }^{\star}\end{array}$ & $95 \% \mathrm{Cl}$ \\
\hline \multirow[t]{3}{*}{ All CHDs } & None & 255 & 12.7 (11.3 to 14.3$)$ & & 1.0 & Ref & 1.0 & Ref \\
\hline & All methods combined $\ddagger$ & 28 & 40.6 (28.9 to 53.1 ) & $<0.001$ & 4.7 & 2.8 to 7.7 & 5.0 & 2.9 to 8.6 \\
\hline & IVF $\pm I C S I \ddagger$ & 25 & 43.1 (30.2 to 56.8 ) & & 5.2 & 3.0 to 8.9 & 5.4 & 3.0 to 9.7 \\
\hline \multirow[t]{3}{*}{ Isolated CHD } & None & 171 & $10.6(9.1$ to 12.2$)$ & & 1.0 & Ref & 1.0 & Ref \\
\hline & All methods combined & 21 & 38.9 (25.9 to 53.1$)$ & $<0.001$ & 5.4 & 3.0 to 9.5 & 5.3 & 2.9 to 9.8 \\
\hline & IVF $\pm I C S I \ddagger$ & 19 & 40.4 (26.4 to 55.7 ) & & 5.7 & 3.1 to 10.4 & 5.7 & 3.0 to 10.8 \\
\hline \multirow{3}{*}{$\begin{array}{l}\text { Isolated major } \\
\text { CHD }\end{array}$} & None & 102 & 16.6 (13.8 to 19.8 ) & & 1.0 & Ref & 1.0 & Ref \\
\hline & All methods combined $\neq$ & 10 & 47.6 (25.7 to 70.2 ) & $<0.001$ & 4.6 & 1.9 to 11.0 & 3.6 & 1.4 to 9.4 \\
\hline & IVF $\pm I C S I \ddagger$ & 9 & 52.9 (27.8 to 77.0$)$ & & 5.6 & 2.1 to 15.0 & 4.0 & 1.4 to 11.2 \\
\hline
\end{tabular}

${ }^{*}$ ORs represent the odds of preterm birth in fetuses with $\mathrm{CHD}$ exposed to infertility treatments relative to the odds of preterm birth in fetuses with CHD unexposed to infertility treatments.

†Adjusted for maternal sociodemographic characteristics (age, geographical origin, occupation), gravidity, diabetes mellitus, vaginal bleeding, invasive prenatal testing, prenatal diagnosis of CHD, intrauterine growth restriction, medical induction of labour or caesarean delivery before labour and year of birth.

flncluding induction of ovulation.

$\mathrm{CHD}$, congenital heart defect; ICSI, intracytoplasmic sperm injection; IVF, in vitro fertilisation; Ref, reference. 


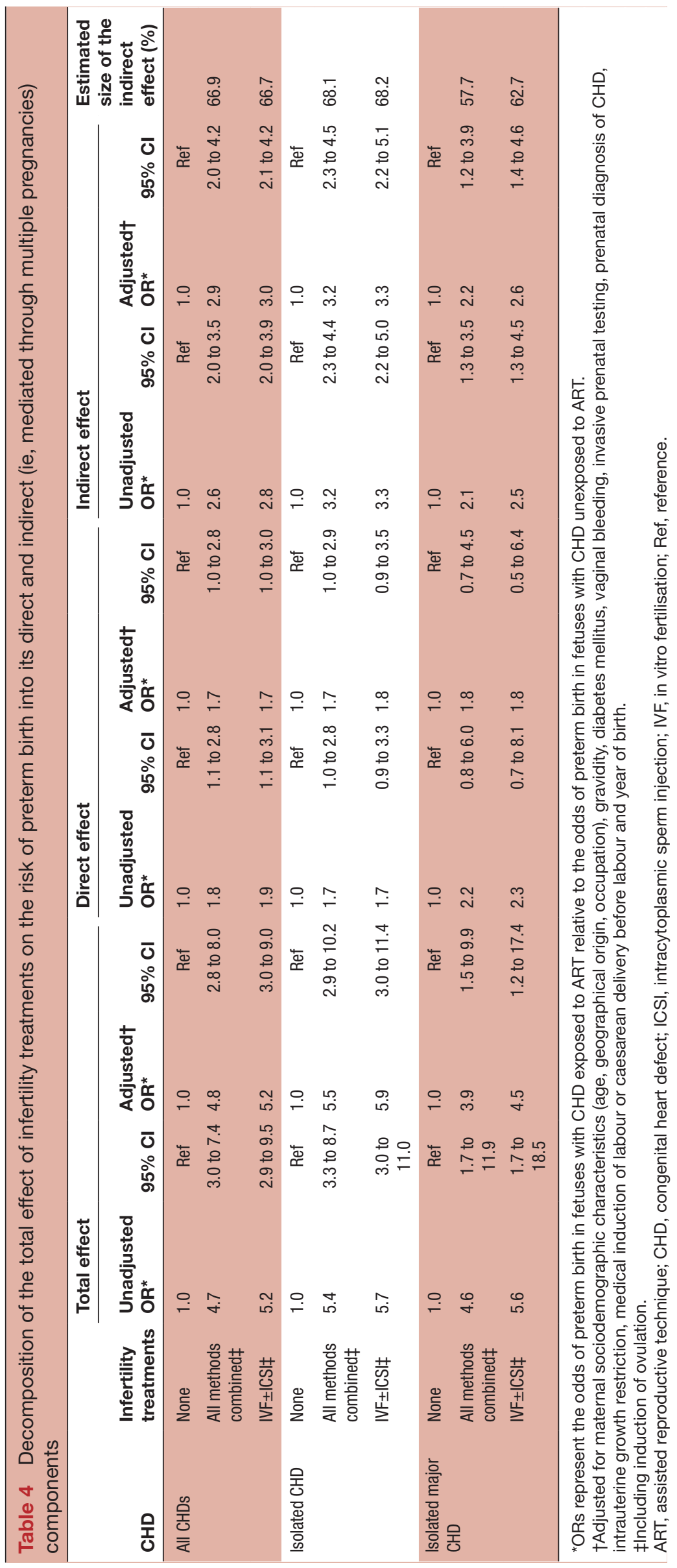


one-third was due to the direct effect of infertility treatments (ie, not mediated by multiple pregnancies).

In general, the exact mechanisms of the association between the higher risk of PTB and multiple pregnancies are not completely known. Multiple pregnancies are known to be associated with the underlying infertility, ${ }^{2} 24$ the vanishing twin syndrome, ${ }^{24}{ }^{25}$ the zygosity (or chorionicity) ${ }^{2627}$ or other maternal characteristics. ${ }^{2}$ However the extent to which these factors may increase the risk of PTB in multiple pregnancies is not known.

Previous studies have shown that the risk of PTB associated with infertility treatments in the general population is not limited to multiple pregnancies. This concurs with our result showing that one-third of the effect on PTB associated with infertility treatments was a 'direct' effect, that is, not mediated by multiple pregnancies.

Our study has certain limitations. We could not conduct detailed separate analyses for categories of CHD, whereas the risk of PTB was shown to vary between categories of CHD. ${ }^{15}$ Data used in this study were collected during the 2005-2008 period and the treatments of infertility have probably evolved since, including their indications. For example ICSI, which was initially indicated almost exclusively in the case of male infertility, is now routinely used in most IVF cycles in France. ${ }^{28}$ Further studies also are needed to assess the specific effects of IVF and ICSI separately, as we had insufficient power to look at IVF alone versus ICSI.

Data on infertility treatments exposure may be incomplete (under-reported) in our study. However, we have no reason to believe that any under-reporting of infertility treatments would be related to PTB. Therefore, misclassification bias according to exposure to infertility treatments is rather unlikely and, if existing, it would be non-differential.

We did not take into account the potential role of vanishing twin syndrome, ${ }^{24}{ }^{25}$ which appears to be more frequent in pregnancies conceived following IVF \pm ICSI. It is therefore possible that some pregnancies that were initially twin pregnancies were finally classified as singleton pregnancies. This classification bias may result in the underestimation of the association between infertility treatments and multiple pregnancies and would lower the estimation of the indirect effect mediated by multiple pregnancies. However, this effect is likely to be small as the percentage of vanishing twin syndrome remains low overall.

Anonymisation of data for our registry does not allow us to identify twins for a given mother. Therefore, we could not account for important correlations that exist between multiple pregnancies, particularly twins.

Analyses were systematically adjusted for year of birth to take into account any potential association of time with infertility treatments and/or risk of PTB, but we did not examine whether infertility treatments effect on PTB changed over time.

Further adjustment for in utero growth retardation did not modify substantially neither our estimates of the risk of PTB associated with infertility treatments nor the quantification of the effect of multiple pregnancies in this association (data not shown). Nevertheless, residual confounding by other characteristics cannot be excluded.

Our study was not designed to and cannot disentangle to what extent the observed association between the risk of PTB and infertility treatments may be due to any causal effects of infertility treatments and/or other factors such as the underlying infertility of couples who conceive following infertility treatments. ${ }^{89} 30$

\section{CONCLUSION}

As many as $41 \%$ of newborns with CHD conceived following infertility treatments were born preterm; this represented a fivefold higher adjusted odds of PTB than that of newborns with CHD conceived spontaneously. Approximately two-thirds of this higher risk of PTB associated with infertility treatments was mediated by multiple pregnancies, whereas a third occurred by mechanisms unrelated to multiple pregnancies. Newborns with CHD conceived following infertility treatments are a particularly high-risk group due to an increased risk of 'double jeopardy' of CHD and PTB.

Collaborators EPICARD STUDY GROUP Principal Investigators: François Goffinet, Babak Khoshnood. Steering Committee: Damien Bonnet (Hôpital Necker Enfants Malades, AP-HP, Centre de référence M3C, Université Paris Descartes, Paris), Johanna Calderon (INSERM U1153), Drina Candilis (Université Paris-Diderot, Paris), Anne-Lise Delezoide (Hôpital Robert Debré, AP-HP, Service de biologie du Développement, Université Paris-Diderot, Paris), Catherine De Vigan (INSERM 1153, Paris), François Goffinet (Groupe Hospitalier Cochin-Hôtel Dieu, AP-HP, Maternité Port-Royal et INSERM U953, Université Paris Descartes, Paris), Lucile Houyel (Hôpital Marie Lannelongue, Service de chirurgie des cardiopathies congénitales, Le Plessis-Robinson), Jean-Marie Jouannic (Hôpital Trousseau, AP-HP, Centre pluridisciplinaire de diagnostic prénatal, UPMC, Paris), Babak Khoshnood (INSERM U1153, Paris), Nathalie Lelong (INSERM U1153, Paris), Suzel Magnier (Hôpital Robert Debré, AP-HP, Service de cardiologie, Paris), Jean-François Magny (Institut de Puériculture et de périnatologie, Service de néonatologie, Paris), Caroline Rambaud (Hôpital Raymond Poincarré, AP-HP, Service d'anatomie et cytologie pathologiques - Médecine légale, UVSQ, Garches), Dominique Salomon (INSERM U1153, Paris), Véronique Vodovar (INSERM U1153, Paris) Project Coordination and Data Analysis Committee: François Goffinet, Babak Khoshnood, Nathalie Lelong, Anne-Claire Thieulin, Thibaut Andrieu, Véronique Vodovar. Independent Data Monitoring Committee (URC Paris Centre et CIC Cochin Necker Mère Enfant): Maggy Chausson, Anissa Brinis, Laure Faure, Maryline Delattre, Jean-Marc Treluyer (Groupe Hospitalier Cochin-Hôtel Dieu, AP-HP, Université Paris Descartes, Paris). External Scientific Committee: Gérard Bréart, Dominique Cabrol, Alain Sérraf, Daniel Sidi, Marcel Voyer. Participating Centers: The Greater Paris Area (Paris and its surrounding suburbs) public (AP-HP) and private maternity units, Departments of Pediatric Cardiology and Pediatric Cardiac Surgery, pediatric cardiologists in private practice, Neonatal Intensive Care Units, Pediatric Intensive Care Units, Emergency Transfer Services (SMUR), Departments of Pathology, Sudden Death Centers, Departments of Family and Infant Protection (DFPE).

Contributors BK conceived the study. KT conducted the statistical analyses and wrote the first draft of the manuscript. NL, FG and BK contributed to the conceptualisation of ideas and made suggestions about the required analyses. All of the authors contributed to the interpretation of findings and revisions of the article.

Funding This work was supported by grants from the Agence de Biomédecine (Saint-Denis La Plaine, France) (to BK). The Paris Registry of Congenital Malformations received financial support from INSERM (Paris, France) and Santé Publique France (Saint-Maurice, France). The EPICARD study was supported by three grants from the Ministry of Health (PHRC 2004, 2008 and 2011). Additional funding for the EPICARD study was provided by the AREMCAR Association (Association pour la Recherche et l'Etude des Maladies Cardiovasculaires). 
Competing interests None declared.

Patient consent Not required.

Provenance and peer review Not commissioned; externally peer reviewed.

Data sharing statement Data cannot be made available for sharing.

Open access This is an open access article distributed in accordance with the Creative Commons Attribution Non Commercial (CC BY-NC 4.0) license, which permits others to distribute, remix, adapt, build upon this work non-commercially, and license their derivative works on different terms, provided the original work is properly cited, appropriate credit is given, any changes made indicated, and the use is non-commercial. See: http://creativecommons.org/licenses/by-nc/4.0/

\section{REFERENCES}

1. Sunderam S, Kissin DM, Crawford SB. Assisted reproductive technology Surveillance - United States, 2014. MMWR Surveill Summ 2017;66:1-24.

2. Blickstein I. Does assisted reproduction technology, per se, increase the risk of preterm birth? BJOG 2006;113(Suppl 3):68-71.

3. D'Angelo DV, Whitehead N, Helms K, et al. Birth outcomes of intended pregnancies among women who used assisted reproductive technology, ovulation stimulation, or no treatment. Fertil Steril 2011;96:314-20.

4. Welmerink DB, Voigt LF, Daling JR, et al. Infertility treatment use in relation to selected adverse birth outcomes. Fertil Steril 2010;94:2580-6.

5. Hansen M, Bower C, Milne E, et al. Assisted reproductive technologies and the risk of birth defects--a systematic review. Hum Reprod 2005;20:328-38.

6. Katalinic A, Rösch C, Ludwig M, et al. Pregnancy course and outcome after intracytoplasmic sperm injection: a controlled, prospective cohort study. Fertil Steril 2004;81:1604-16.

7. Wen J, Jiang J, Ding C, et al. Birth defects in children conceived by in vitro fertilization and intracytoplasmic sperm injection: a metaanalysis. Fertil Steril 2012;97:1331-7.

8. Davies MJ, Moore VM, Willson KJ, et al. Reproductive technologies and the risk of birth defects. N Engl J Med 2012;366:1803-13.

9. Reefhuis J, Honein MA, Schieve LA, et al. Assisted reproductive technology and major structural birth defects in the United States. Hum Reprod 2009;24:360-6.

10. Tararbit K, Houyel L, Bonnet D, et al. Risk of congenital heart defects associated with assisted reproductive technologies: a populationbased evaluation. Eur Heart J 2011;32:500-8.

11. Tararbit K, Lelong N, Thieulin AC, et al. The risk for four specific congenital heart defects associated with assisted reproductive techniques: a population-based evaluation. Hum Reprod 2013;28:367-74.

12. Dolk H, Loane MA, Abramsky L, et al. Birth prevalence of congenital heart disease. Epidemiology 2010;21:275-7.

13. Khoshnood B, Lelong N, Houyel L, et al. Prevalence, timing of diagnosis and mortality of newborns with congenital heart defects: a population-based study. Heart 2012;98:1667-73.
14. Malik S, Cleves MA, Zhao W, et al. Association between congenital heart defects and small for gestational age. Pediatrics 2007;119:e976-82.

15. Laas E, Lelong N, Thieulin AC, et al. Preterm birth and congenital heart defects: a population-based study. Pediatrics 2012;130:e829-37.

16. Tanner K, Sabrine N, Wren C. Cardiovascular malformations among preterm infants. Pediatrics 2005;116:e833-38.

17. Natarajan G, Anne SR, Aggarwal S. Outcomes of congenital heart disease in late preterm infants: double jeopardy? Acta Paediatr 2011;100:1104-7.

18. Swenson AW, Dechert RE, Schumacher RE, et al. The effect of late preterm birth on mortality of infants with major congenital heart defects. J Perinatol 2012;32:51-4.

19. Goldenberg RL, Culhane JF, lams JD, et al. Epidemiology and causes of preterm birth. Lancet 2008;371:75-84

20. Jenkins KJ, Correa A, Feinstein JA, et al. Noninherited risk factors and congenital cardiovascular defects: current knowledge: a scientific statement from the American Heart Association Council on Cardiovascular Disease in the Young: endorsed by the American Academy of Pediatrics. Circulation 2007;115:2995-3014.

21. Erikson R, Goldthorpe JH, Jackson M, et al. On class differentials in educational attainment. Proc Natl Acad Sci U S A 2005;102:9730-3.

22. Buis ML. Direct and indirect effects in a logit model. Stata $J$ 2010;10:11-29.

23. Ancel PY, Goffinet F, et al, EPIPAGE-2 Writing Group. Survival and morbidity of preterm children born at 22 through 34 weeks' gestation in France in 2011: results of the EPIPAGE-2 cohort study. JAMA Pediatr 2015;169:230-8.

24. Pinborg A, Wennerholm UB, Romundstad LB, et al. Why do singletons conceived after assisted reproduction technology have adverse perinatal outcome? Systematic review and meta-analysis. Hum Reprod Update 2013;19:87-104.

25. van Oppenraaij RH, Jauniaux E, Christiansen OB, et al. Predicting adverse obstetric outcome after early pregnancy events and complications: a review. Hum Reprod Update 2009;15:409-21.

26. Aston KI, Peterson CM, Carrell DT. Monozygotic twinning associated with assisted reproductive technologies: a review. Reproduction 2008;136:377-86.

27. Knopman JM, Krey LC, Oh C, et al. WITHDRAWN: What makes them split? Identifying risk factors that lead to monozygotic twins after in vitro fertilization. Fertil Steril 2013.

28. Agence de Biomédecine, 2015. Activité d'assistance médicale la procréation. https://www.agence-biomedecine.fr/annexes/ bilan2016/donnees/procreation/01-amp/pdf/amp.pdf [Accessed Aug 18 2006].

29. Rimm AA, Katayama AC, Katayama KP. A meta-analysis of the impact of IVF and ICSI on major malformations after adjusting for the effect of subfertility. J Assist Reprod Genet 2011;28:699-705.

30. Zhu JL, Basso O, Obel C, et al. Infertility, infertility treatment, and congenital malformations: Danish national birth cohort. BMJ 2006;333:679. 